\title{
金属材料の引張疲労変形*
}

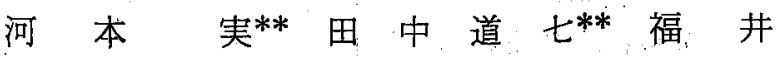

\section{Tensile Fatigue Deformation of Metals} \\ by

\section{Minoru Kawamoto, Tsuneshichi Tanaka and Jun Húkui \\ (Kyoto University)}

洵***

One of the authors has reported previously on the fatigue deformation of various steels. under repeated bending and torsion. In this report some experiments about the tensile fatigue deformation of the mild steel and $6: 4$ brass were carried out.

Results obtained are as follows:

(1) Fatigue deformation grows rapidly and reaches certain amount of value at the beginning of stress repetition, and thereafter the continuous increase of deformation can hardly be observed for both materials. But sometimes the discontinuous increase of deformation takes place after considerable repetition of stress cycles under the stress near the endurance limit or above it, and this phenomenon is observed markedly for the mild steel.

(2) For the mild steel which has the apparent yield point in static test, the fatigue yield limit agrees with the static lower yield point. While for the brass which has no such yield point in static test, the fatigue yield limit does not agree with static ones, and is considerably less than it.

(Received Sep. 27, 1958)

\section{1. 緒 容}

種々の鋼材の豊げおよびねじり疲爫変形については さきに報告したが，本研究では，静試験において明暸 な降伏点を有する村料として軟鋼を，明暸な降伏点を 示さない材料として黄銅を用いて引張疲労变形に関す る夷験を行い，疲学によるこの種の材料の変形機構を 調へ，また，痩労降伏限度を求めて静降伏点との関俰 を明らかにした。

\section{2. 実験材料および実験方法}

実験に供した材料は 0.21\%C 炭素鋼および $6: 4$ 黄 銅の 2 種類であって，これらの化学成分を Table 1 に, 警処理および機械的性質を Table 2 に示した。

試験片の形状および寸法は Fig. 1 に示すとおりで あって，(a)は軟鋼，(b)は黄銅試験片で,それぞれ 寸法は異なるが，試験部分は互に相似な形状を有して いる。なお，試験片は熱処理後機械仕上げした。
使用した試験機は Haigh 式引張庄縮疲労試験機で 繰返速度は約 $1800 \mathrm{rpm}$ である。

試験片の伸びの測定は Fig. 2 に示す装置を用いて おこなった。すなわち，'試験片 3 に図のように金具 1 および 2 を取り付け，金具 1 に取り付けられた距離棒

Table 1 Chemical composition of materials

\begin{tabular}{|c|c|c|c|c|c|c|}
\hline \multirow{2}{*}{ Material } & \multirow{2}{*}{ Symbol } & \multicolumn{5}{|c|}{ Chemical composition (\%) } \\
\hline & & C & $\mathrm{Si}$ & $\mathrm{Mn}$ & $P$ & $\mathbf{S}$ \\
\hline Mild steel & $ヒ-2796$ & $0 \cdot 21$ & 0.25 & 0.58 & 0.030 & 0.042 \\
\hline \multirow{2}{*}{ Material } & \multirow{2}{*}{ Symbol } & \multicolumn{5}{|c|}{ Chemical composition $(\%)$} \\
\hline & & $\mathrm{Cu}$ & $\mathrm{Zn}$ & $\mathrm{Sn}$ & $\mathrm{Pb}$ & $\mathrm{Fe}$ \\
\hline Brass & - & $59 \cdot 74$ & $36 \cdot 95$ & 1.06 & $1 \cdot 82$ & 0.43 \\
\hline
\end{tabular}

Table 2 Heat treatment and mechanical properties of materials

\begin{tabular}{|c|c|c|c|c|c|c|c|c|c|}
\hline Material & Sy mbol & Heat treatment & $\begin{array}{l}\text { Upper yleld } \\
\text { point } \\
\sigma \text { so } \\
\left(\mathrm{kg} / \mathrm{mm}^{2}\right)\end{array}$ & $\mid \begin{array}{c}\text { Lower yield } \\
\text { point } \\
\sigma_{s u} \\
\left(\mathrm{~kg} / \mathrm{mm}^{2}\right)\end{array}$ & $\begin{array}{c}\text { Ultimate } \\
\text { strength } \\
\sigma B \\
\left(\mathrm{~kg} / \mathrm{mm}^{2}\right)\end{array}$ & $\begin{array}{c}\text { Breaking } \\
\text { strength on } \\
\text { final area } \\
\sigma T^{+} \\
\left(\mathrm{kg} / \mathrm{mm}^{2}\right)\end{array}$ & $\begin{array}{c}\text { Elongation } \\
\varphi \\
(\%)\end{array}$ & $\mid \begin{array}{c}\text { Reduction } \\
\text { of area } \\
\psi \\
(\%)\end{array}$ & $\begin{array}{l}\text { Young's } \\
\text { modulus } \\
E \\
\left(\mathrm{~kg} / \mathrm{mm}^{2}\right)\end{array}$ \\
\hline Mild steel & ヒ-2795 & $875^{\circ} \mathrm{C} 1 \mathrm{hr}$ Anneal & $28 \cdot 7$ & $26 \cdot 8$ & $52 \cdot 1$ & $87 \cdot 9$ & $55 \cdot 0$ & $28 \cdot 9$ & $2 \cdot 14 \times 10^{4}$ \\
\hline brass & - & $600^{\circ} \mathrm{C} \frac{1}{2}$ hr Anneal & $20 \cdot 9^{*}$ & 一 & $44 \cdot 2$ & $54 \cdot 3$ & $26 \cdot 6$ & $21 \cdot 4$ & $1.02 \times 10^{4}$ \\
\hline
\end{tabular}

* 黄銅の降伏点は0.2\%の永久ひずみを生ずる店力である.

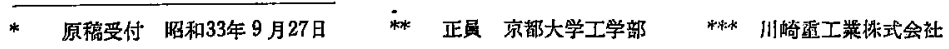




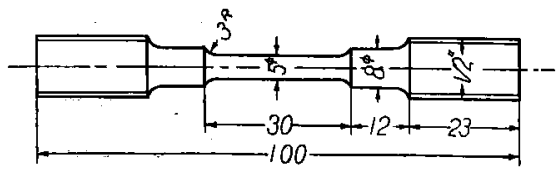

(a)

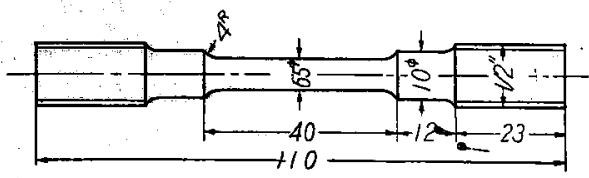

(b)

Fig. 1 Test specimens

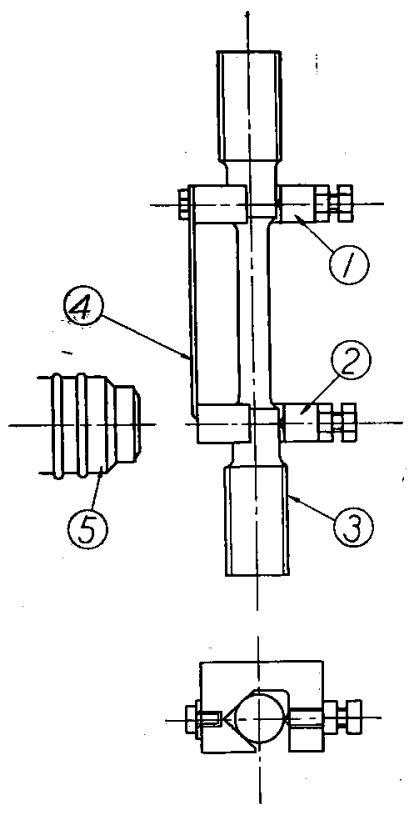

Fig. 2 Measuring apparatus

4 の下端と金具 2 に引いた標線との相対的な位固を読 取顕微鏡 5 で測定寸ることにより求めた。なお，こう して得た測定值より試騟片のひずみを算出する際，金 具 1 およひ 2 を取り付けた段つきの部分のひずみは無 視した。

実験は，軟鋼については両振および片振の場合のほ 力, 応力振幅 $\sigma_{a}$ を $18,15,10 \mathrm{~kg} / \mathrm{mm}^{2}$ とし, 平均応 力を種々に変化させた場合，および平均応 力 $\sigma_{m}$ を $10 \mathrm{~kg} / \mathrm{mm}^{2}$ とし, 応力振幅を種々 に変化させた場合の全部で 6 種類，黄銅に ついては両振および片振の場合のほか， $\sigma_{n}$ を $14,12,8,4 \mathrm{~kg} / \mathrm{mm}^{2}$ とし, 平均応力を 種々に変化させた場合の6 種類について行 った。また，疲労変形は両振の場合を除い たすべての試験片について湘定した。

\section{3. 実験結果およひその考察}

軟鋼および黄銅について疲爫試験の結果，得られた $S-N$ 線図を両振，片振および平均応力 $\sigma_{m}$ を一定と した部分両振の量合について示すと，それぞれ Fig. 3 およびFig. 4 のようになる：ただし，縦軸には応力 振幅 $\sigma_{a}$ と平均応力 $\sigma_{m}$ の和である最大応力 $\sigma_{\max }$ を とってある。

また，前述のように㪀鋼および黄銅について，両振 の場合を除いた，それぞれ 5 種類の応力状熊に関して 疲学変形を測定した結果を，数軸に水久ひずみ $\varepsilon_{p}$ を \%でとり，横軸に応力繰返数 $N$ を対数でとって示すと Fig. 5〜9および Fig. 10〜14 のようになる.

こ扎らの図からわかるように，一定の平均応力のる とで応力振幅を与えた場合，陚驗片に生ずる永久变形 は㳄鋼および黄銅のいずれの材料に対しても耐久限度 の上下を問わず，疲労のごく初期に急激に起り，繰返 数 $N て ゙$ 約 $5 \times 10^{3}$ 以前にすでにある一定值に近づいて それ以後は連続的な増加はほとんど見られない。しか し，応力が耐久限度付近あるいはそれ以上の場合には，

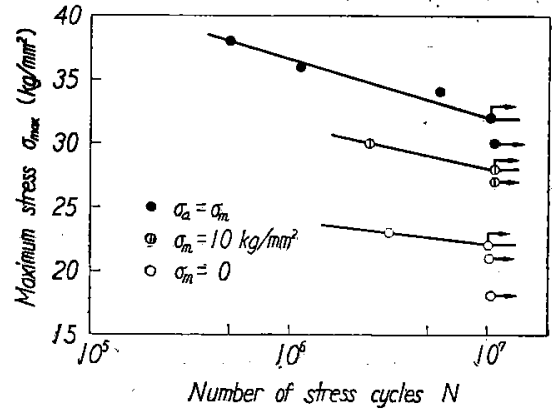

Fig. $3 S-N$ diagram for mild steel

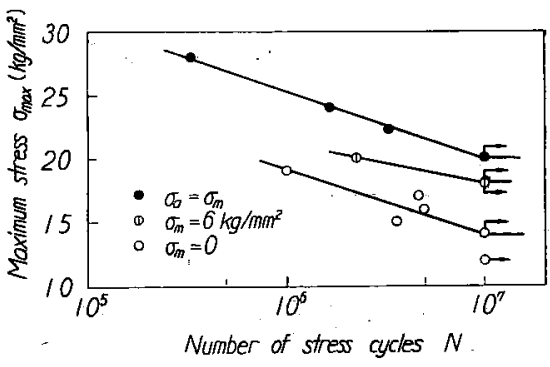

Fig. $4 \quad S-N$ diagram for brass

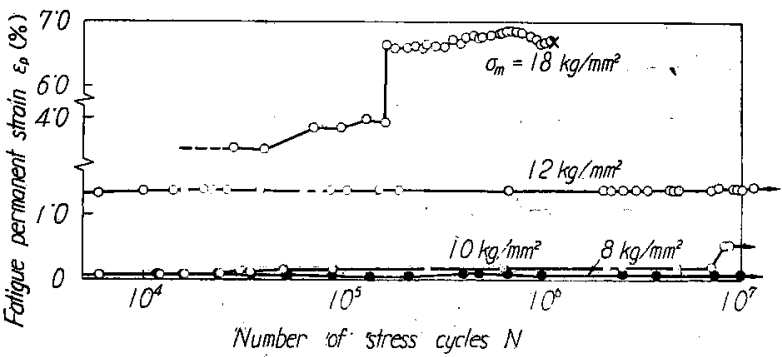

Fig. $5 \varepsilon_{p}-N$ diagram for mild steel $\left(\sigma_{n}=18 \mathrm{~kg} / \mathrm{mm}^{2}\right)$ 


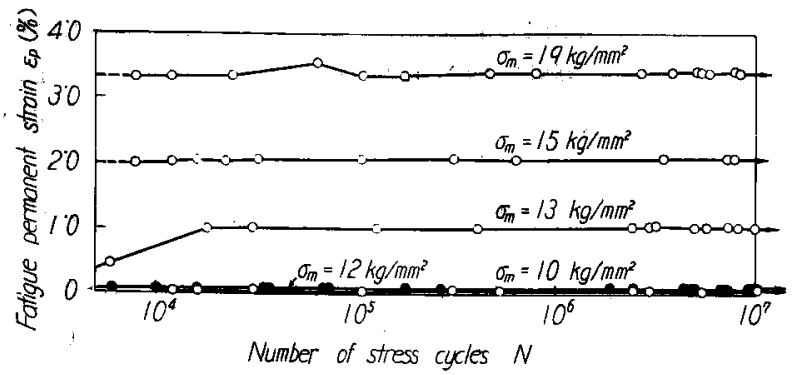

Fig. $6 \varepsilon_{p}-N$ diagram for mild steel $\left(\sigma_{b b}=15 \mathrm{~kg} / \mathrm{mm}^{2}\right)$

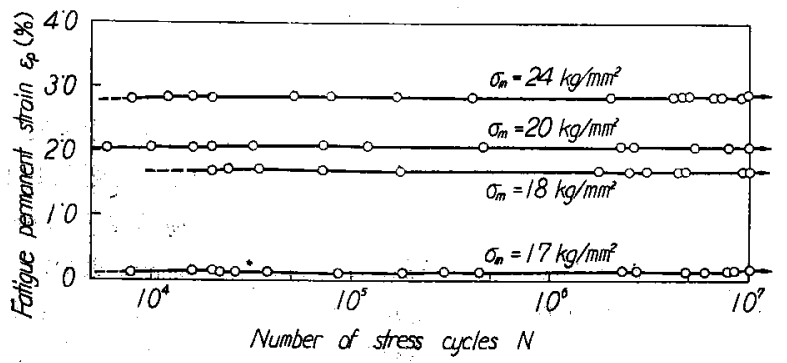

Fig. $7 \varepsilon_{p}-N$ diagram for mild steel $\left(\sigma_{n}=10 \mathrm{~kg} / \mathrm{mm}^{2}\right)$

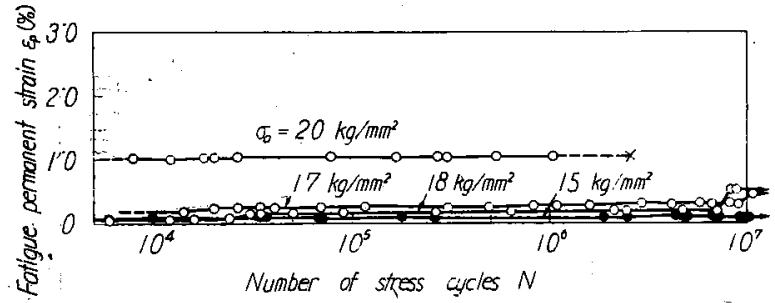

Fig. $8 \varepsilon_{p}-N$ diagram for mild steel $\left(\sigma_{m}=10 \mathrm{~kg} / \mathrm{mm}^{2}\right)$

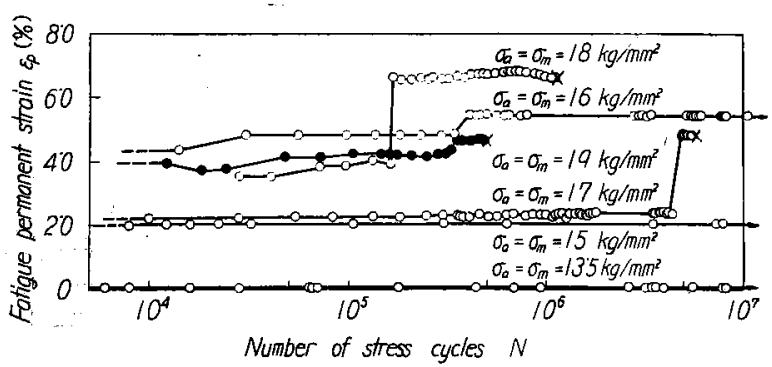

Fig. $9 \varepsilon_{p}-N$ diagram for mild steel $\left(\sigma_{a}=\sigma_{m}\right)$

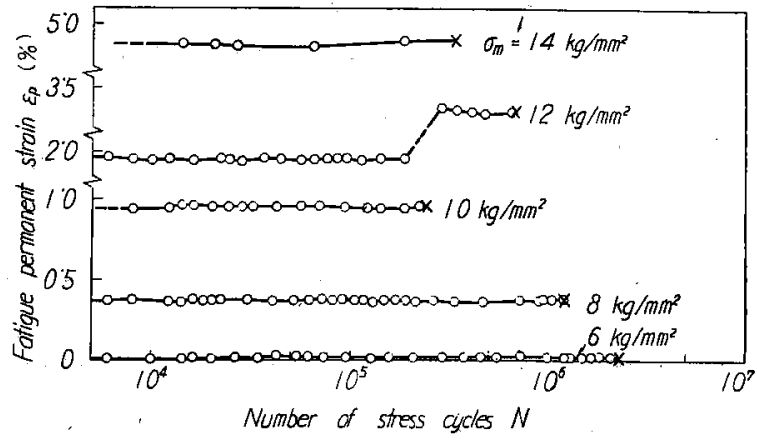

Fig. $10 \varepsilon_{p}-N$ diagram for brass $\left(\sigma_{a}=14 \mathrm{~kg} / \mathrm{mm}^{2}\right)$
上に述べたような初期に起る変形以外にあ る繰返数で不連続的に变形が增加する現象 が見られ，その場合の変形は初期における 変形の 2 倍以上に達することが多い、この 現象は枚鋼の札じ疲労の場合にもすでに 見られたものであるが，Fig. 10 および

Fig. 11 見ると, 黄銅のように明暸な降 伏点をもたない材料でも权鋼はど顕著では ないが；やはり観察されることがわかる。

以上の寒験結果をもとにして，糈軸に疲 労試験の際の最大応力をとり，横軸には破 断した試驗片については破断直前の，破断 しなかった試験片については $N=10^{7}$ 付近 の最終ひずみ測定時における最大ひずみを とって, 疲労試験の際の応力とひずみの関 係を静試験において求めた応力ーひずみ線 図と比較すると Fig. 15 および Fig. 16 の ようになる、ただし Fig. 15 は軟鋼, Fig. 16 は黄銅に関するもので, いずれも応力振 幅をパラメータとした場合についてのみ示 した。

Fig. 15 より明らかなように，軟鋼につ いては疲労試験の際の最大応力が静試験に おける下降伏点に達するまでは疲労による 降伏は起らないが, 最大応力がそれ以上に 大きくなると疲労による变形はもはや最大 応力のみではきまらず，応力振幅 $\sigma_{a}$ と平 均応力 $\sigma_{m}$ の組み合わせによって異なって くる、そして応力振幅が小さくなるに従っ てしだいに静試験における応力ーひずみ線 図に近づく傾向が見られる，また，疲労変 形は一般に静試験における变形よりも大き いが，応力振幅の高い場合には降伏点に近 いところで，かえって疲労变形が静試験に おける変形より小さい場合も見られる：

いっぽう，黄銅の場合にはFig. 16 を見 ると，応力振幅の大なる場合には軟鋼にお けると同様に，疲労試験の際の応力ーひず み線図が一部分静試験における応力ーひず み線図の上にでる場合があるが，それ以外 では，疲労变形はすべて静試験における变 形よりも大きく，また，静降伏点よりも低 い最大応力で疲学による降伏が起っている ことがわかる。

そこで，これらの図から㳄鋼については $\varepsilon_{p}=0.2 \%, 1.0 \%$ および $3.0 \%$, 黄銅に ついは $\varepsilon_{p}=0.2 \%, 0.5 \%$ よび1.0\%の? 永久ひずみを生ずる最大応力 $\sigma_{\max }$ を求め 


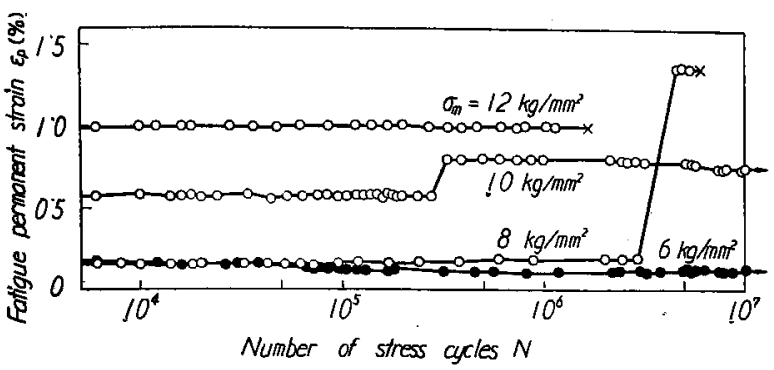

Fig. $11 \varepsilon_{p}-N$ diagram for brass $\left(\sigma_{n}=12 \mathrm{~kg} / \mathrm{mm}^{2}\right)$

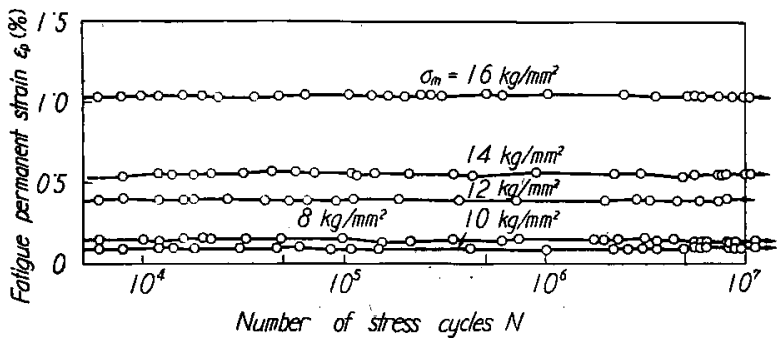

Fig. $12 \varepsilon_{p}-N$ diagram for brass $\left(\sigma_{a}=8 \mathrm{~kg} / \mathrm{mm}^{2}\right)$

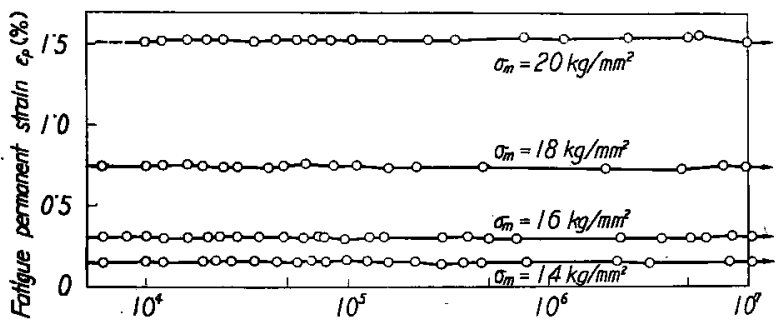

Fig. $13 \varepsilon_{p}-N$ diagram for brass $\left(\sigma_{a}=4 \mathrm{~kg} / \mathrm{mm}^{2}\right)$

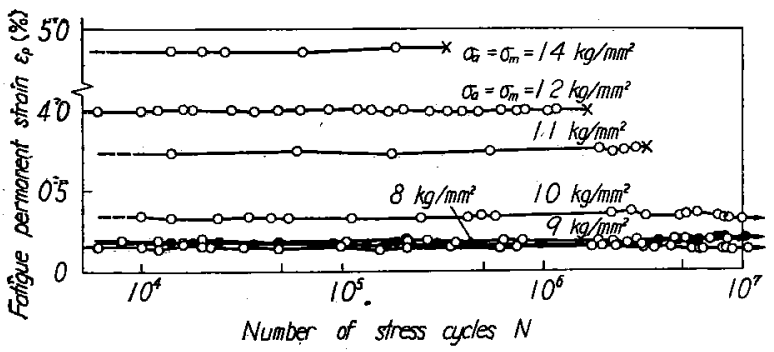

Fig. $14 \varepsilon_{p}-N$ diagram for brass $\left(\sigma_{n}=\sigma_{m}\right)$

Table 3 Maximum stress yielding the constant permanent strain of the mild steel for the static and fatigue tests

\begin{tabular}{|c|c|c|c|c|}
\hline \multirow{2}{*}{. } & \multirow{2}{*}{$\begin{array}{c}\text { Stress } \\
\text { amplitude } \\
\sigma a \\
\left(\mathrm{~kg} / \mathrm{mm}^{2}\right)\end{array}$} & \multicolumn{3}{|c|}{ Maximum stress } \\
\hline & & $\begin{array}{l}(\sigma \operatorname{mgx}) 0 \cdot 2 \% \\
\left(\mathrm{~kg} / \mathrm{mm}^{2}\right)\end{array}$ & $\begin{array}{c}(\sigma \max ) 1^{\circ} 0 \% \\
\left(\mathrm{~kg} / \mathrm{mm}^{2}\right)\end{array}$ & $\begin{array}{l}(\sigma \max ) 3.0 \% \\
\left(\mathrm{~kg} / \mathrm{mm}^{2}\right)\end{array}$ \\
\hline \multirow{3}{*}{$\begin{array}{l}\text { Fatigue } \\
\text { test }\end{array}$} & 18 & $26 \cdot 7$ & $29 \cdot 2$ & $32 \cdot 6$ \\
\hline & 15 & $27 \cdot 1$ & $28 \cdot 0$ & $32 \cdot 7$ \\
\hline & 10 & $27 \cdot 0$ & $27 \cdot 5$ & $34 \cdot 5$ \\
\hline Static test & 0 & $26 \cdot 8$ & $26 \cdot 8$ & $37 \cdot 1$ \\
\hline
\end{tabular}

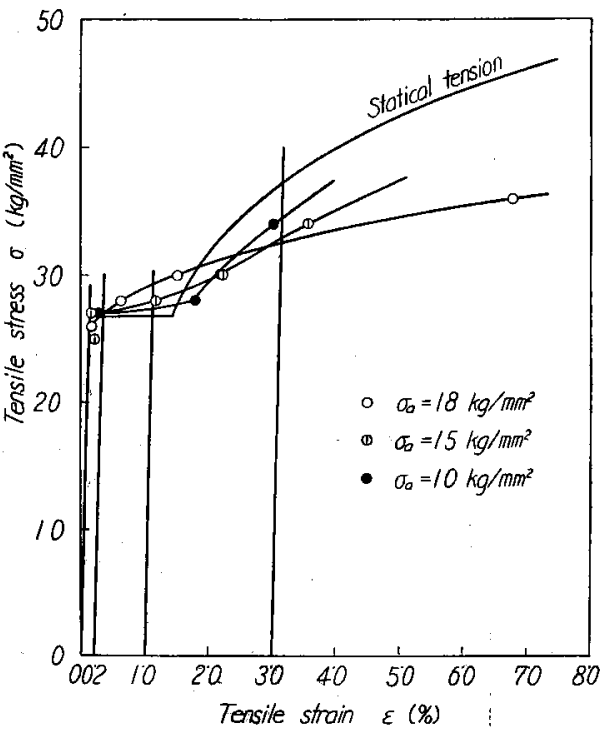

Fig. 15 Tensile stress-strain diagram in static and fatigue test for mild steel

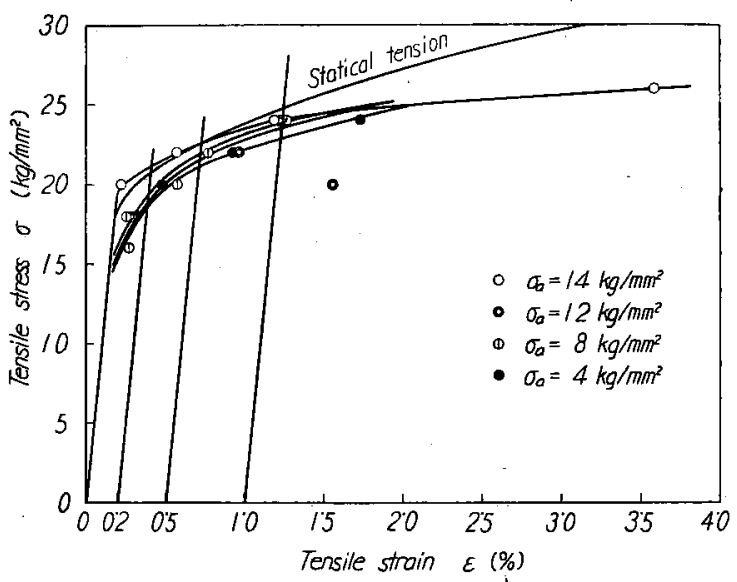

Fig. 16 Tensile stress-strain diagram in static and fatigue test for brass

Table 4 Maximum stress yielding the constant permanent strain of the brass for the static and fatigue tests

\begin{tabular}{|c|c|c|c|c|}
\hline & \multirow{2}{*}{$\begin{array}{c}\text { Stress } \\
\text { amplitude } \\
\sigma_{a} \\
\left(\mathrm{~kg} / \mathrm{mm}^{2}\right)\end{array}$} & \multicolumn{3}{|c|}{ Maximum stress } \\
\hline & & $\begin{array}{l}(\sigma \operatorname{mgx}) 0 \cdot 2 q \\
\left(\mathrm{~kg} / \mathrm{mm}^{2}\right)\end{array}$ & $\left(\begin{array}{c}\sigma \max ) 0 \cdot 5 g \\
\left(\mathrm{~kg} / \mathrm{mm}^{2}\right)\end{array}\right.$ & $\begin{array}{l}\left(\sigma_{\max }\right) 1 \cdot 0 \% \\
\left(\mathrm{~kg} / \mathrm{mm}^{2}\right)\end{array}$ \\
\hline . & 14 & $21 \cdot 1$ & $22 \cdot 4$ & $24 \cdot 1$ \\
\hline Fatigue & 12 & $19 \cdot 4$ & $22 \cdot 0$ & $23 \cdot 9$ \\
\hline \multirow[t]{2}{*}{ test } & 8 & $18 \cdot 9$ & $21 \cdot 6$ & $23 \cdot 5$ \\
\hline & 4 & $18 \cdot 7$ & $21 \cdot 2$ & $22 \cdot 8$ \\
\hline Static test & 0 & $20 \cdot 9$ & $22 \cdot 6$ & $24 \cdot 9$ \\
\hline
\end{tabular}




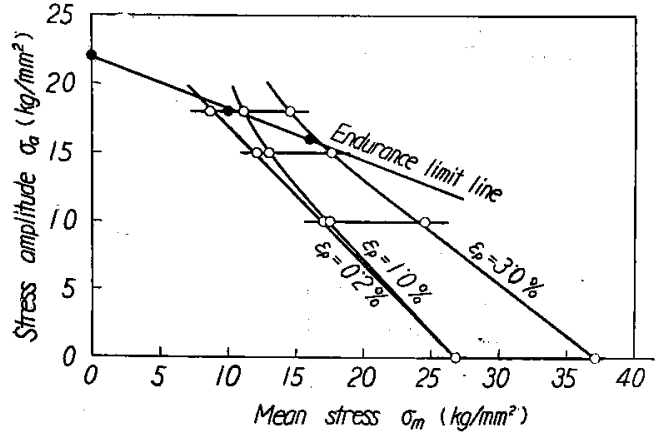

Fig. 17 Diagram of endurance limit and fatigue deformation for mild steel

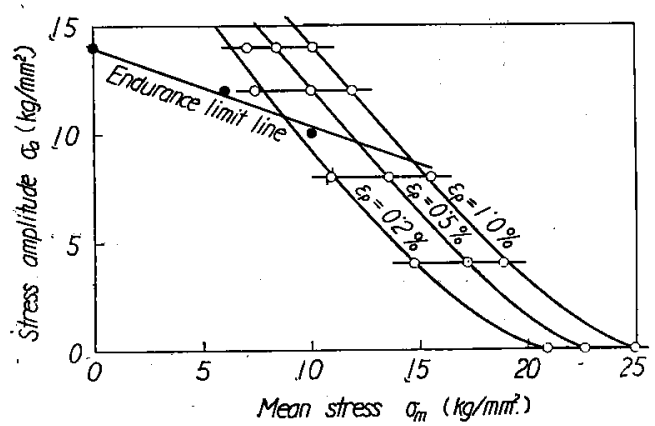

Fig. 18 Diagram of endurance limit and fatigue deformation for brass.

て疲学試験と静試験の場合を比較すると Table 3 およ び Table 4 のようになる.

Fig. 17 および Fig. 18 は軟鋼および黄銅について， Table 3 执よひ Table 4 をむとにして，一定の永久 ひずみを生ずる応力振幅 $\sigma_{a}$ および平均応力 $\sigma_{m}$ を耐 久限度線図上に示したものである.なお，これらの図 で黑丸は Fig. 3 および Fig. 4 に示した $S-N$ 線図 から求めた耐久限度の值である。

さて，変形に対しては永久ひずみ $\varepsilon_{p}=0.2$ 名を生ず るときを実際に使用することのできる極限とすれば， これらの図において，両軸と耐久限度線および $\varepsilon_{p}=$ $0.2 \%$ の曲線で表わされる疲学降伏限度線によって囲 まれた部分が，それぞれの材料の安全使用範囲を決定 することになる。ところで：この疲労降代限度線は， 静試験において明暸な降伏点を有する吹鋼で恃静的な 下隆伏点を示す横䡛上の点をとおって $45^{\circ}$ の傾斜をな
す直線となるに対しここのような降代点を持たない黃 銅では，沙莋伏点をとおって $45^{\circ}$ の傾斜をなす值線と は一致せず，安全使用簀围を狭める側をとおっている ことがわかる、ゆえに，曲げおよびねじり疲労に関す る先の報告をも考虑すれば，すへての応力状態に対し て, 後者のような材料の使用に際しては，その安全使 用䈌罒の決定にあたって耐久限度線之同様に疲労降伏 限度線を求めておくことが必要である。

\section{4. 結言}

本研究により得られた結果を要約すれば次のとおり である。

（1）平均庥力を伴う引張疲労試験において発生す る疲労変形は，軟鋼および黄銅のいずれの材料に対し ても，絽返数のごく初期に急激に起り，それ以後は連 続的な增加はほとんど見られない。しかし，応力が耐 久限度付近あるいはそれ以上の場合には，上のような 変形以外にある絽返数で不連続的に変形が增加する現 象が見られる。そして，この現象は㳄鋼の場合に特に 顕著であるが，黄銅の場合においてもやはり観察する ことができる。

（2）静試験において明暌な降伏点を有する軟鋼で は，疲労試鍳の際の最大応力が静試験における下降伏 点以下の場合は疲労による降伏は起らず, 疲労降伏限 は静試験における下降伏点に一致する。しかし，最大 応力がこの降伏限を越えている場合は, 疲労変形はも はや最大応力のみによってはきまらず，応力振幅と平 均応力の組み合わせによって異なり，応力振幅が小さ いほど静試験における变形に近づいてくる、いっぱう， 静試験において明暸な降伏点を示さない黄銅において は，疲労降伏限は静降伏点よりも低くなる，京た，颙 鋼および黄銅のいずれにおいても，疲労変形は一般に 静試験における変形よりも大きいが，応力振幅の高い 場合にはある籁囲で，逆に静試験にお忖る变形よりも 小さい疲学変形を示すことがある。

(3) 以上の結果および先の曲げおよびねじり疲労 に関する報告より，明瞭な降伏点を示さない材料の使 用に際しては，すべての応力状態に対して疲労降伏限 度について充分注意を払う必要がある。

\section{参 考 文 献}

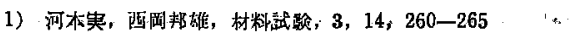

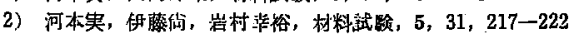

